\title{
Relationships between Fluoride Intake, Urinary Fluoride Excretion and Fluoride Retention in Children and Adults: An Analysis of Available Data
}

\author{
A. Villa ${ }^{a} \quad$ M. Anabalon ${ }^{a} \quad$ V. Zohouri ${ }^{b} \quad$ A. Maguire ${ }^{c} \quad$ A.M. Franco ${ }^{d}$ \\ A. Rugg-Gunnc \\ a Institute of Nutrition and Food Technology, INTA, University of Chile, Santiago, Chile; b Teesside University, \\ Middlesbrough, and ${ }^{\mathrm{C}}$ Newcastle University, Newcastle upon Tyne, UK; ${ }^{\mathrm{d}}$ Antioquia University, Medellin, Colombia
}

\section{Key Words}

Fluoride metabolism • Fluoride retention estimation •

Fluoride urinary excretion

\begin{abstract}
The aim of this study was to examine the relationship between total daily fluoride intake (TDFI), daily urinary fluoride excretion (DUFE) and fractional fluoride retention (FFR) using available data, in order to clarify the ability of DUFE to predict TDFI and, therefore, the risk of fluorosis development. Examination of published reports of simultaneous measurement of TDFI and DUFE, together with data from two unpublished Chilean studies, yielded data for 212 children aged less than 7 years and for 283 adults aged 18-75 years, providing a total of 212 and 269 data points, respectively. The relationship between DUFE and TDFI was studied for children and adults, separately. Daily fluoride retention (DFR) was estimated as a function of TDFI in children and adults assuming an average $90 \%$ fluoride absorption, and the numerical relationships between the estimated FFR and the TDFI were explored. Limiting FFR values of 0.55 and 0.36 were found for children and adults, respectively, above a threshold of TDFI of 0.5 and 2 mg, respectively. Neutral fluoride balances were predicted when the TDFI was equal to approximately $0.07 \mathrm{mg}$ F/day for children and $0.8 \mathrm{mg}$ F/day for adults. For children and adults, it is possible to obtain rea-
\end{abstract}

sonably good estimations of community-based TDFI and DFR, using DUFE data. The advantages and limitations of these relationships, together with the need for future studies, are discussed.

Copyright $\odot 2010$ S. Karger AG, Basel

The general features of fluoride metabolism in humans are well understood. It is generally accepted that fluoride retention occurs almost entirely in hard tissues and that fluoride retention in soft tissues is almost negligible [Whitford, 1990, 1996]. In addition, urinary fluoride excretion is the most important metabolic pathway for fluoride elimination from the body, faecal fluoride excretion amounting to approximately $10 \%$ of the total daily fluoride intake (TDFI) in children and adults [Spencer et al., 1970; Maheshwari et al., 1981; Ekstrand et al., 1984, 1994].

A low prevalence and severity of dental fluorosis can be apparent even with low fluoride intakes and prevalence and severity increase with increasing chronic fluoride intake during the first few years of life [Burt and Fejerskov, 1996]. Although it has an empirical origin, a daily fluoride dose of between 0.05 and $0.07 \mathrm{mg} \mathrm{F} / \mathrm{kg}$ body weight/day proposed by the American Academy of Pediatrics [1986] has been generally accepted as 'a useful upper limit for fluoride intake in children' [Burt, 1992]. The

\section{KARGER}

Fax +4161306 1234 E-Mail karger@karger.ch www.karger.com (c) 2010 S. Karger AG, Basel

$0008-6568 / 10 / 0441-0060 \$ 26.00 / 0$

Accessible online at:

www.karger.com/cre
Alberto E. Villa

Microminerals Laboratory, Institute of Nutrition and Food Technology, INTA

University of Chile, El Líbano 5524

Santiago (Chile)

Tel./Fax +56 2221 2249, E-Mail avilla@inta.cl 
phrase 'a useful upper limit for fluoride intake in children' refers to a situation under which the dental caries incidence will be minimised while the risk of dental fluorosis would also be minimal. Skeletal fluorosis occurs with higher fluoride intakes [Hodge and Smith, 1977], where water fluoride concentrations are above $8 \mathrm{mg} / \mathrm{l}$, for example in South Africa [Ockerse, 1946] and India [Srikantia and Siddiqui, 1965]. The prevalence and severity of both dental and skeletal fluorosis are strongly related to the degree of fluoride exposure, although they differ considerably in their threshold of exposure [National Research Council, 2006].

While, in the past, water fluoride concentration was a reasonable predictor of fluoride intake and risk of dental fluorosis, the increase in availability and ingestion of fluoride from other sources, e.g. fluoride toothpaste, fluoridated salt, fluoride tablets, fluoridated milk or bottled water [Levy et al., 2001; Zohouri et al., 2003; Whelton et al., 2004; Do and Spencer, 2007; Maguire et al., 2007; Rodrigues et al., 2009], and the greater awareness of the effect of drying foods over fluoride-rich coal fires in greatly increasing the fluoride concentration in these foods [Fawell et al., 2006] undermines this simple assumption. Therefore, to assess risk adequately, obtaining an estimate of fluoride intake is required. Measuring fluoride intake is possible but requires good co-operation from subjects, skilled staff to record intake and is usually expensive. If it were possible to obtain valid predictions of fluoride intake from measurements of urinary fluoride excretion, the risk of dental and skeletal fluorosis might be assessed more easily, since collecting urine for fluoride measurement is relatively simple [Marthaler, 1999; Villa et al., 2000, 2008; Franco et al., 2005]. In addition, assessing fluoride exposure at the time of risk to the developing dentition and skeleton is obviously preferable to waiting several years for fluorosis to become clinically evident.

The proportion of ingested fluoride that is retained has been thought to be around 50\% [WHO, 1994] and likely to vary with age [WHO, 1994]; this information has been obtained, however, from individual studies. In addition, there is less information on how the proportion of fluoride retained varies with fluoride intake and age. These are important steps in estimating risk.

While the first reports of simultaneous measurement of TDFI and daily urinary fluoride excretion (DUFE) were published many years ago, several studies have been undertaken recently (partly due to the need to learn of the relative importance of the many sources of ingested fluoride and the increasing risk of dental fluo- rosis) in children [Ekstrand et al., 1984, 1994; Villa et al., 2000; Zohouri and Rugg-Gunn, 2000; Haftenberger et al., 2001; Franco et al., 2005; Zohouri et al., 2006; Maguire et al., 2007] and adults [Maheshwari et al., 1981; Spencer et al., 1970, 1975; Villa et al., 2004, 2008]. It was thought desirable to bring this information together so as to examine more closely the relationship between TDFI, DUFE and daily fluoride retention (DFR) in order to assist understanding of these physiological variables. Thus, the aims of this investigation were to use available data to: (1) examine the relationship between TDFI and DUFE, taking age into account, and assess the suitability of DUFE as a predictor of TDFI, (2) explore the relationship between TDFI and DFR in order to aid interpretation of the above relationship in the assessment of risk of dental and skeletal fluorosis, and (3) examine the extent of fractional fluoride retention (FFR) limits as TDFI increases and determine the value of that limit.

\section{Materials and Methods}

\section{Published Results}

Following a search of internationally available literature, all reports providing individual data of measured TDFI together with simultaneously measured DUFE in children and adults were included in this study (tables 1,2 ). Those studies that only reported average values of TDFI and corresponding average DUFE data were also included since the current authors provided the original databases for this present study. As there is only 1 published study in adolescents $(n=19)$ [Villa et al., 2004], this age group was not considered.

\section{Additional Studies}

Data from 2 additional studies, carried out in 2 Chilean locations between 2003 and 2005, were included. These studies [Villa et al., unpubl.], of preschool children and adults aged $18-75$ years, were carried out in El Olivar and Iquique, communities with fluoride concentrations in their drinking water of 0.06 and $1.1 \mathrm{mg}$ $\mathrm{F} / \mathrm{l}$, respectively (tables 1,2 ).

The materials and methods used in these Chilean unpublished studies were the same as those reported in detail in previous papers [Villa et al., 2000, 2004, 2008]. In brief, individual assessments were made of TDFI, including beverages, food and swallowed fluoride toothpaste together with the corresponding DUFE data. In all of the Chilean studies, customised or standardised diets were used while, in the rest of the studies, customary fluoride intake conditions were recorded. Summary information concerning these 2 unpublished studies is given in table 3 .

\section{Database}

All of the available individual data pairs of TDFI and the corresponding DUFE from young children and adults appearing in the literature were used to prepare two separate databases. The number of subjects, their age and gender, and other characteris- 
Table 1. Summary of reported TDFI and DUFE in children aged 0.15-7 years from different countries

\begin{tabular}{|c|c|c|c|c|c|}
\hline Survey & Country & $\begin{array}{l}\text { Age, } \\
\text { years }\end{array}$ & $\mathrm{n}$ & $\begin{array}{l}\text { Average daily } \\
\text { F intake, } \mathrm{mg} / \text { day }\end{array}$ & $\begin{array}{l}\text { Average } 24 \text {-hour F urinary } \\
\text { excretion, mg/day }\end{array}$ \\
\hline Ekstrand et al. [1984] & Sweden & $0.19-0.54$ & 5 & 0.011 & 0.030 \\
\hline Ekstrand et al. [1984] & Sweden & $0.15-0.31$ & 5 & 0.861 & 0.360 \\
\hline Ekstrand et al. [1994] & USA & $0.22-1.16$ & 4 & 0.190 & 0.144 \\
\hline Villa et al. [2000] & Chile & $3-5$ & 20 & 1.02 & 0.358 \\
\hline Haftenberger et al. [2001] & Germany & $3-6$ & 11 & 0.931 & 0.476 \\
\hline Franco et al. [2005] & Colombia & $4-6$ & 96 & $0.93-1.96^{1}$ & $0.290-0.528^{1}$ \\
\hline Zohouri et al. [2006] & UK & $1-3$ & 7 & 0.71 & 0.33 \\
\hline Maguire et al. [2007] & UK & $6-7$ & 29 & $0.736-1.043^{1}$ & $0.203-0.323^{1}$ \\
\hline Villa et al. [unpubl.] & Chile & $3-5$ & 35 & $0.335-1.95^{1}$ & $0.126-0.887^{1}$ \\
\hline
\end{tabular}

$\mathrm{n}=$ Number of subjects.

${ }^{1}$ Range of intakes and excretions reported according to differently fluoridated areas.

Table 2. Summary of reported TDFI and DUFE in adults aged $18-75$ years

\begin{tabular}{llllll}
\hline Survey & Country & Age, years & $\mathrm{n}$ & Average daily F intake, mg/day & $\begin{array}{c}\text { Average 24-hour F urinary } \\
\text { excretion, mg/day }\end{array}$ \\
& & & & & 7.52 \\
Spencer et al. [1970] & USA & $30-53$ (males) & 10 & 13.79 NaF supplementation & 2.20 \\
Spencer et al. [1975] & USA & $39-53$ (males) & 4 & 4.35 & 0.75 \\
Maheshwari et al. [1981] & USA & $20-45$ (males) & 9 & 0.41 low-F diet & 3.57 \\
Maheshwari et al. [1981] & USA & $20-45$ (males) & 8 & 5.40 F supplementation (5 mg) \\
Maheshwari et al. [1981] & USA & $20-45$ (males) & 4 & 10.38 F supplementation (10 mg) & 6.76 \\
Villa et al. [2004] & Chile & $19-73$ (both genders) & 73 & $1.77-2.48$ (3 age subgroups) & $1.32-1.68(3$ age subgroups) \\
Villa et al. [2008] & Chile & $20-40$ (females) & 60 & 1.82 & 1.24 \\
Villa et al. [unpubl.] & Chile & $18-75$ (both genders) & 115 & $0.53-2.97^{1}$ & $0.49-2.08^{1}$
\end{tabular}

$\mathrm{n}=$ Number of subjects. The total number of subjects was 283. In the report by Maheshwari et al., data for some subjects were grouped so that for the studies involving 9, 8 and 4 subjects, the number of data pairs was 4,2 and 1, respectively. The number of data pairs available for inclusion in analyses was, therefore, 269.

${ }^{1}$ Range of intakes and excretions according to different dietary fluoride regimens.

Table 3. Summary of data from unpublished F intake and excretion studies carried out for young children and adults in 2 Chilean communities (El Olivar and Iquique) with different naturally occurring F concentrations (0.06 and $1.1 \mathrm{mg} / \mathrm{l}$, respectively) in the drinking water

\begin{tabular}{lccll}
\hline Community & Age, years & $\mathrm{n}$ & Average daily F intake \pm SD, mg/day & Average daily F excretion \pm SD, mg/day \\
\hline El Olivar & $3-5$ & 20 & $0.34 \pm 0.06(0.31-0.36)$ & $0.13 \pm 0.04(0.11-0.15)$ \\
& $19-71$ & 58 & $0.53 \pm 0.12(0.50-0.56)$ & $0.49 \pm 0.20(0.45-0.54)$ \\
\hline Iquique & $3-5$ & 15 & $1.95 \pm 1.02(1.44-2.46)$ & $0.89 \pm 0.31(0.73-1.05)$ \\
& $18-75$ & 57 & $2.97 \pm 0.87(2.75-3.19)$ & $2.08 \pm 0.66(1.91-2.25)$
\end{tabular}

Figures in parentheses indicate $95 \%$ CI. 


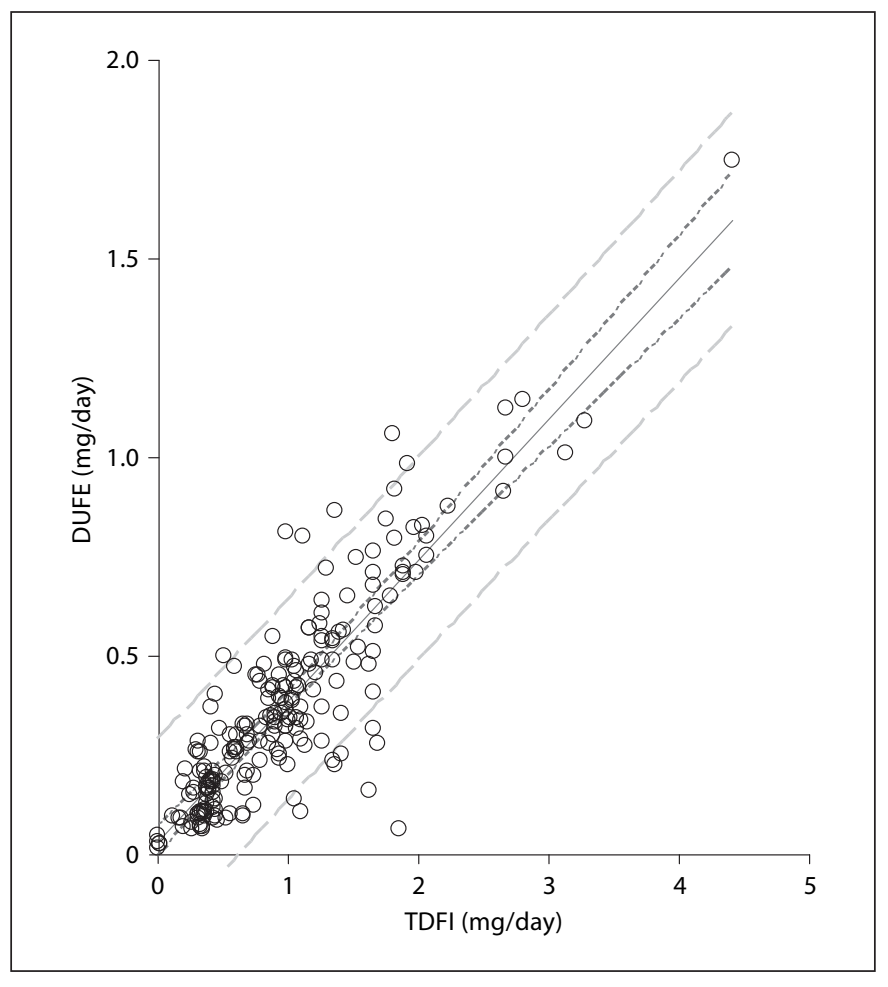

Fig. 1. Relationship between DUFE and TDFI for 212 young children (table 1) aged 0.15-7 years recorded in 9 studies in 6 countries. The full line is the best fit; the inner interrupted lines indicate the $95 \% \mathrm{CI}$ of the regression, and the outer interrupted lines indicate the $95 \%$ PI.

tics of these studies, together with the main features of their results, are summarised in table 1 (for infants and children up to 7 years of age) and table 2 (for young, middle-aged and elderly adults, 18-75 years). In the study of Ekstrand et al. [1994], the 4 subjects took part in 3 separate experiments. Data in their table 1 (regimen A) have been used in our study in order to avoid including more than 1 value for any individual. In addition, within regimen A, where multiple recordings were made for an individual, mean values for that individual were used. In the study of Spencer et al. [1970], the same subjects were studied over time; data recorded during the supplementation phase were used in our study. In the study of Maheshwari et al. [1981], data for subjects are grouped - data for these groups have been used in our study, as indicated in the footnote to table 2.

\section{Data Analysis}

The databases were managed using Microsoft Excel 2003. Linear relationships between variables and comparison of slopes and intercepts were analysed with Analyse-it 2.12 for Excel and for Stata 8, respectively. The level of significance was set at $\mathrm{p}<0.05$.

\section{Mathematical Calculations}

As shown in figures 1 and 2 (see Results), linear relationships were obtained when DUFE was plotted against TDFI both for

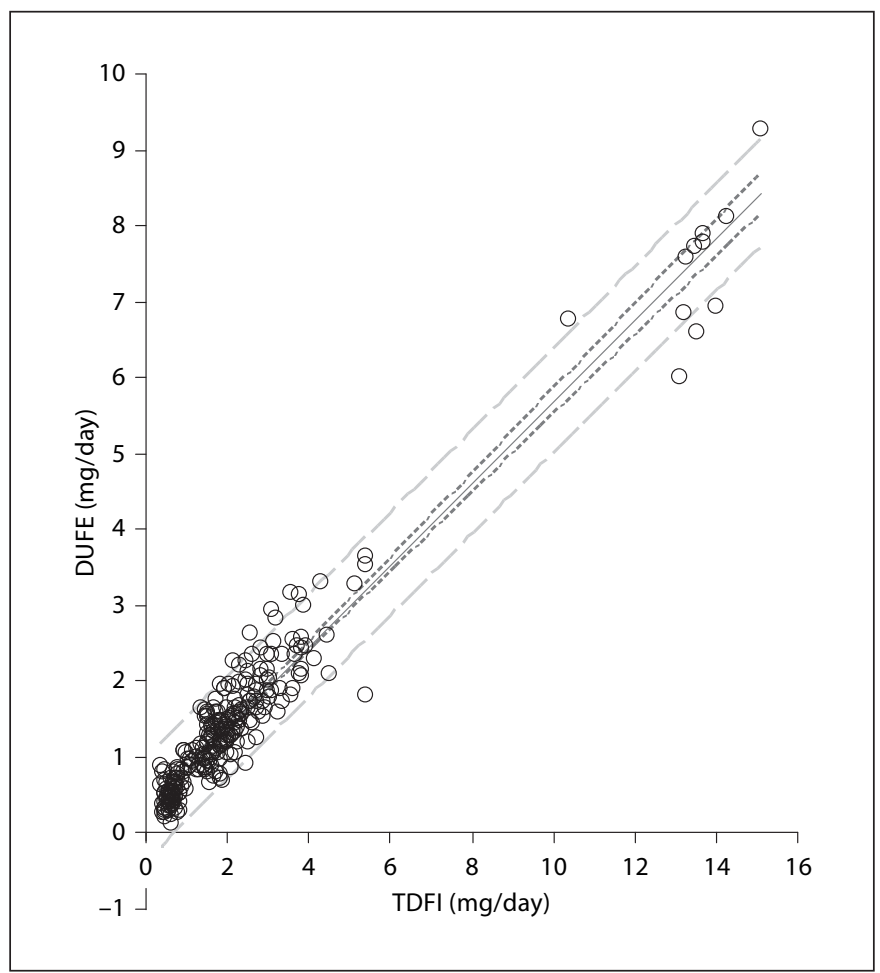

Fig. 2. Relationship between DUFE and TDFI for 269 data pairs from adults (table 2) aged 18-75 years recorded in 8 studies in 2 countries. The full line is the best fit; the inner interrupted lines indicate the $95 \%$ CI of the regression, and the outer interrupted lines indicate the $95 \%$ PI.

children and adults. The general mathematical expression for these relationships is:

$$
\text { DUFE }=a+(b \times \text { TDFI })
$$

where ' $a$ ' is the intercept and ' $b$ ' the slope of the linear relationship. DFR was calculated assuming an average constant value of $90 \%$ for fluoride absorption as a proportion of total fluoride intake. Thus, DFR was estimated from the mass balance equation:

$$
\mathrm{DFR}=(0.9 \times \mathrm{TDFI})-\mathrm{DUFE}
$$

When substituting DUFE in equation 2 by its mathematical relationship with TDFI as described in equation 1 and factoring out the variable TDFI, equation 3 is obtained:

$$
\mathrm{DFR}=-\mathrm{a}+[(0.9-\mathrm{b}) \times \mathrm{TDFI}]
$$

The proportion of fluoride retained (FFR) from the TDFI was estimated as the amount of fluoride retained based on equation 3 divided by the TDFI. When dividing both sides of equation 3 by TDFI, equation 4 is obtained:

$$
\mathrm{FFR}=(\mathrm{DFR} / \mathrm{TDFI})=(0.9-\mathrm{b})-(\mathrm{a} / \mathrm{TDFI})
$$

For the sake of clarity, units were not included in the above equations. Throughout this paper the units are milligrams fluoride per day. FFR is, by definition, dimensionless. Neutral fluoride meta- 


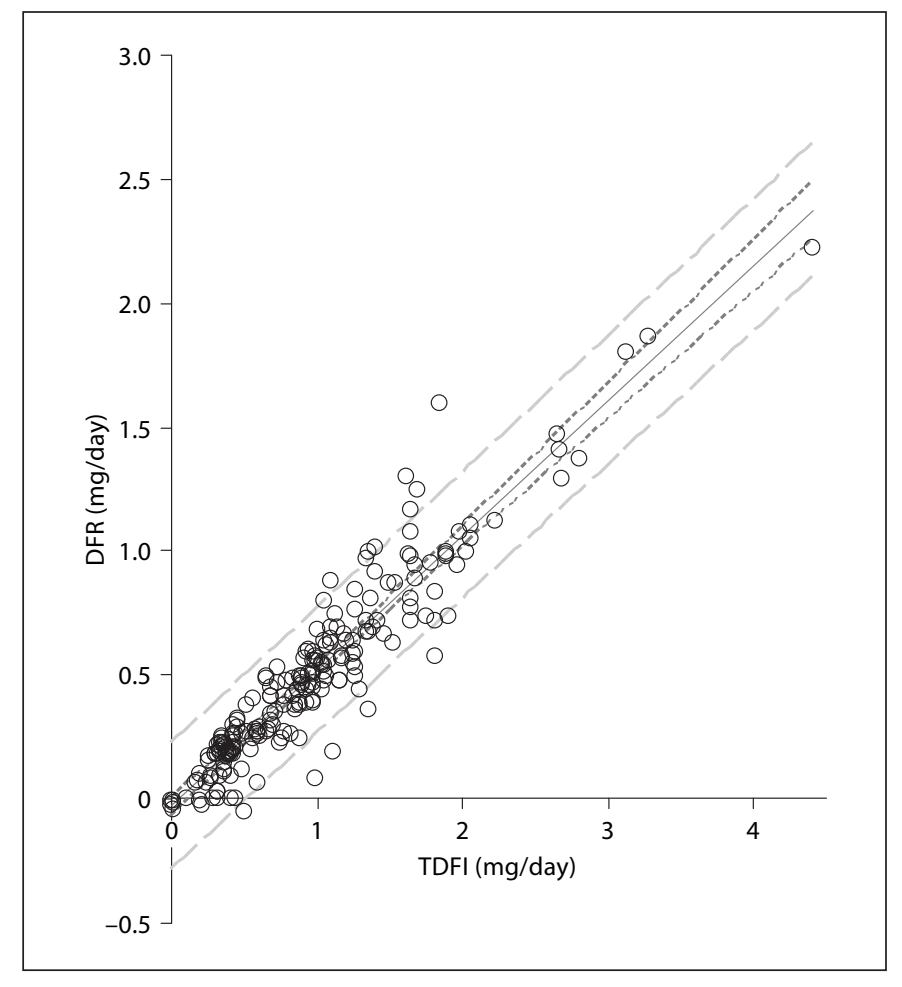

Fig. 3. Relationship between estimated DFR and TDFI for 212 young children (table 1 ) aged $0.15-7$ years. The full line is the best fit; the inner interrupted lines indicate the $95 \%$ CI of the regression, and the outer interrupted lines indicate the 95\% PI.

bolic balance will be established when FFR $=0$. From equation 3 , a neutral fluoride balance will be reached when the TDFI is:

TDFI (neutral balance) $=\mathrm{a} /(0.9-\mathrm{b})$

The limiting FFR value, i.e. the maximum value that can be reached by FFR when TDFI increases to very high values, is given by equation 6 :

FFR (limiting value $)=0.9-\mathrm{b}$

\section{Results}

A preliminary, separate analysis of the results from the Iranian study [Zohouri and Rugg-Gunn, 2000] showed a significant linear relationship $(\mathrm{p}<0.005)$ when DUFE was plotted against the TDFI for young children living in non-fluoridated communities ( $\mathrm{n}=78$ data pairs). However, the slope and intercept of the best-fit line were highly statistically significantly different from the corresponding values of the best-fit line of the rest of the 212 data pairs shown in figure 1 (ANCOVA; $p<0.001$ ). For this reason, these 78 data pairs were not included in the

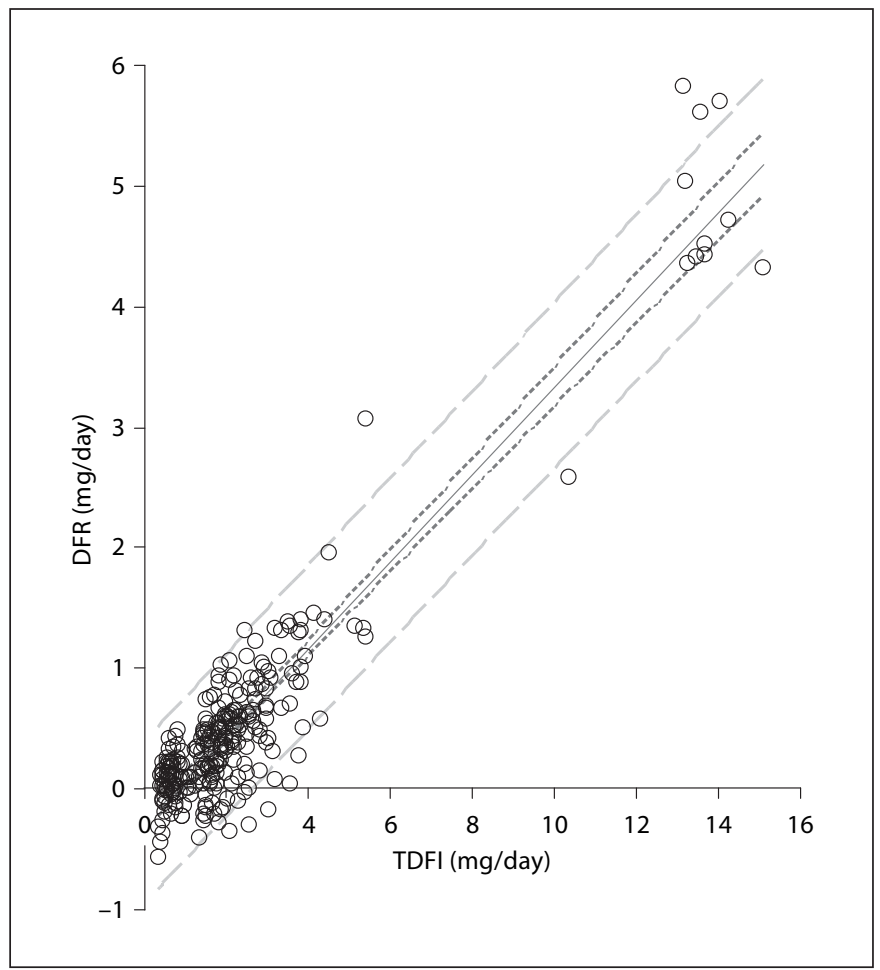

Fig. 4. Relationship between estimated DFR and TDFI for 269 data pairs from adults (table 2) aged 18-75 years. The full line is the best fit; the inner interrupted lines indicate the $95 \% \mathrm{CI}$ of the regression, and the outer interrupted lines indicate the 95\% PI. current study (see Discussion). A graphical presentation of the relationship between fluoride excretion and intake was reported previously [Zohouri and Rugg-Gunn, 2000]. Thus, there were 212 data pairs for young children (table 1) and 269 for adults (table 2).

Figure 1 shows the linear relationship obtained when DUFE was plotted against TDFI for young children. The best-fit line (full line) is shown together with the $95 \%$ confidence interval (CI) of the regression (inner dashed lines) and the 95\% prediction interval (PI; outer dashed lines). Figure 2 shows the linear relationship obtained when DUFE was plotted against TDFI for adults. Again, the bestfit line is shown together with the $95 \%$ CI of the regression and the 95\% PI. Figures 3 and 4 show the linear relationships obtained when the estimated DFR was plotted against TDFI for young children and adults, respectively.

Table 4 provides a summary of the regression data, statistical values and comparisons from figures $1-4$. The slopes and intercepts together with the corresponding standard error values, $p$ values and $\mathrm{R}^{2}$ values are reported for each of the linear relationships shown in figures 1-4. 
Table 4. Summary of regression data of $\mathrm{F}$ excretion versus $\mathrm{F}$ intake, and $\mathrm{F}$ retention versus $\mathrm{F}$ intake for children and adults, and comparison of the slopes and intercepts for both age groups by ANCOVA

\begin{tabular}{|c|c|c|c|c|c|c|c|}
\hline \multirow[t]{2}{*}{ Age group } & \multirow[t]{2}{*}{ Slope } & \multirow{2}{*}{$\begin{array}{l}\text { Slope } \\
\text { p value }\end{array}$} & \multirow[t]{2}{*}{ Intercept } & \multirow{2}{*}{$\begin{array}{l}\text { Intercept } \\
\mathrm{p} \text { value }\end{array}$} & \multirow[t]{2}{*}{$\mathrm{R}^{2}$} & \multicolumn{2}{|c|}{ ANCOVA $p$ values } \\
\hline & & & & & & slope & intercept \\
\hline \multicolumn{8}{|c|}{ Excretion versus intake } \\
\hline Children & $0.35 \pm 0.01$ & $<0.001$ & $0.03 \pm 0.02$ & 0.026 & 0.76 & & \\
\hline Adults & $0.54 \pm 0.01$ & $<0.001$ & $0.29 \pm 0.03$ & $<0.001$ & 0.94 & $<0.001$ & $<0.001$ \\
\hline \multicolumn{8}{|c|}{ Retention versus intake } \\
\hline Children & $0.55 \pm 0.01$ & $<0.001$ & $-0.03 \pm 0.02$ & 0.026 & 0.89 & & \\
\hline Adults & $0.36 \pm 0.01$ & $<0.001$ & $-0.29 \pm 0.03$ & $<0.001$ & 0.88 & $<0.001$ & $<0.001$ \\
\hline
\end{tabular}

${ }^{1} \mathrm{p}$ values for the comparison of slopes and intercepts of both age groups.

The comparisons between each slope and intercept for the two age groups (ANCOVA) are shown in the last two columns of table 4.

From equation 5, and using the slopes and intercepts reported in table 4, estimations of TDFI leading to neutral fluoride balance, i.e. FFR $=0$, were performed for children and adults. These values were 0.07 and $0.82 \mathrm{mg}$ F/day for children and adults, respectively.

Figures 5 and 6 show the relationship of calculated FFR with increasing TDFI for children and adults, respectively. For TDFI values lower than $0.5 \mathrm{mg} / \mathrm{day}$, there is a marked increase in the FFR values for children and adults with increasing TDFI. On the other hand, for TDFI values higher than approximately $0.5 \mathrm{mg} /$ day for children and $2 \mathrm{mg}$ /day for adults, the FFR estimated values tend to reach limiting values. The FFR limiting values $( \pm 95 \% \mathrm{CI})$ were calculated from equation 6 as $0.55( \pm 0.03)$ and 0.36 $( \pm 0.02)$ for children and adults, respectively.

\section{Discussion}

Recent publication of a number of studies of simultaneous measurement of TDFI and DUFE has allowed a more comprehensive analysis of the relationship between these variables using data from over 200 young children and over 200 adults. The results showed, first, that there was a strong linear relationship between TDFI and DUFE, but with different slopes for young children and adults, second, a strong linear relationship between DFR and TDFI, with different slopes for young children and adults, and, third, for TDFI over a low threshold $(0.5 \mathrm{mg} /$ day for children and $2 \mathrm{mg} /$ day for adults) that FFR for young chil- dren and adults were relatively constant at 0.55 and 0.36 , respectively. With certain caveats (see below) these results allow acceptable estimates of TDFI from recorded DUFE for populations and, therefore, predictions of risk of fluorosis.

The nature of the data collected places some restrictions on the external validity of the findings. First, in several studies, some subjects were investigated more than once. In order to avoid errors inherent in multiple recording of the same subject, data from only one study were included when subjects participated in more than one study, and mean values were used when subjects had more than one recording in the same study, as described in Materials and Methods and footnote to tables 1 and 2. Second, in all of the studies included, subjects consumed 'westernised' diets. The one published study of subjects consuming a 'non-westernised', more vegetarian, diet [Zohouri and Rugg-Gunn, 2000] reported a relationship between TDFI and DUFE (see Results) which differed from those presented in table 1 . It is known that a vegetarian diet results in more alkaline urine which, in turn, leads to increased urinary fluoride excretion [Whitford, 1990, 1996]. In support of these physiological findings, Awadia et al. [1999] reported that, in a Tanzanian population, non-vegetarians had a 7 times greater risk of developing dental fluorosis compared with vegetarians. Thus, caution is needed when using the findings in the present publication in populations consuming a 'nonwesternised' diet.

The third cautionary note concerns age. Only one published report was found $(n=19)$ of subjects between the ages 7-18 years, and this was considered insufficient to analyse and include. Because fluoride retention is re- 


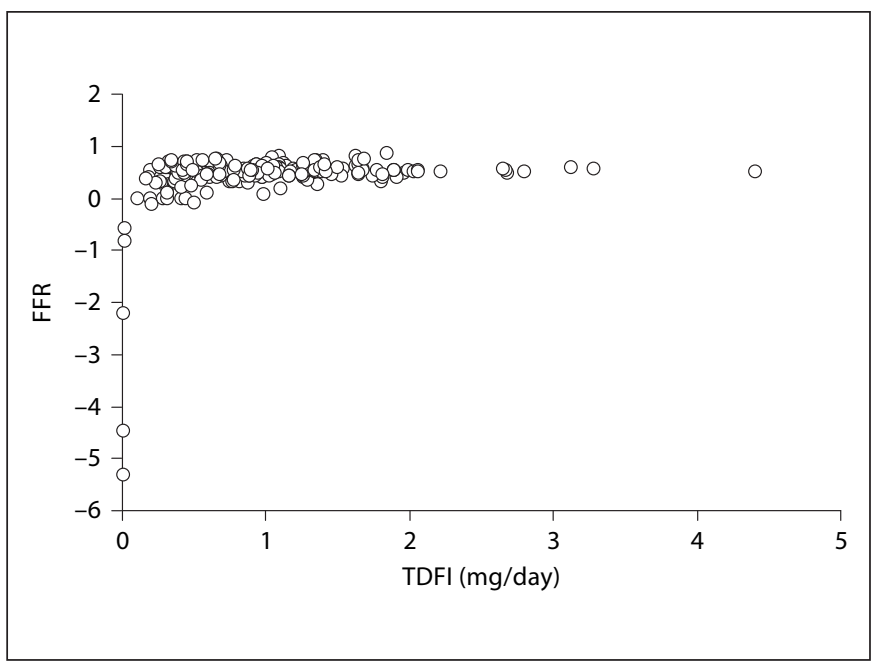

Fig. 5. Relationship between calculated FFR and TDFI for 212 young children (table 1 ) aged $0.15-7$ years.

lated to skeletal maturity and the skeleton matures fairly progressively with age, there is likely to be a rather continuous change in fluoride retention with age. However, in the present study, in order to generate relatively large numbers of subjects for analysis, it was decided to create two age groups - young children $(<7$ years) and adults (18-75 years).

There are two further aspects of the data used in these analyses which are worth noting. First, in some of the studies, data were obtained from one 24-hour measurement of fluoride intake and urinary collection while, in other studies, the data pairs were the means of more than one 24-hour period per subject - in some studies they were the means of a 6 -day record - reducing the variance compared with a single 24 -hour measurement. Second, in some of the studies, as pointed out in Materials and Methods, subjects consumed a standardised diet (although the amount of water consumed was not controlled but was measured) while, in other studies, dietary intake was not standardised. The former method will reduce the variance of the total daily fluoride intake compared with the latter method. These two differences in method are considered unlikely to have any significant effect on the conclusions of the study where the conclusions are relevant to studies on groups of people rather than individuals.

Regarding the use of the results for predicting TDFI, figures 1-4 indicate that, although the $\mathrm{R}^{2}$ values were high, the ample 95\% PI band associated with the regres-

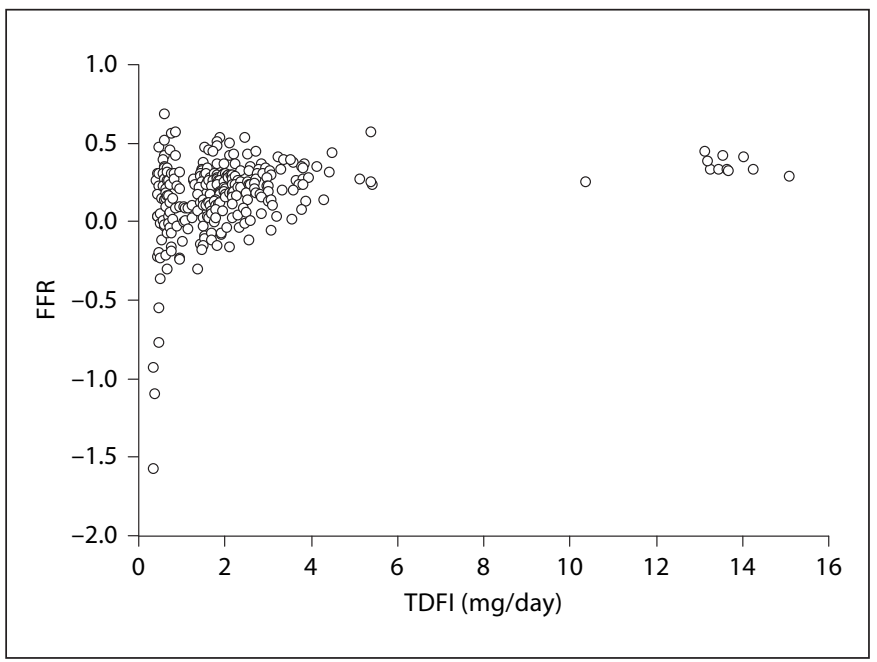

Fig. 6. Relationship between calculated FFR and TDFI for 269 data pairs from adults (table 2) aged 18-75 years.

sion lines does not allow the use of DUFE as a precise estimator of either the TDFI or DFR on an individual basis. However, the 95\% CI bands are narrow enough to allow the estimation of average TDFI and DFR in children and adults from average DUFE values, i.e. on a community basis. It is remarkable that highly significant, simple linear relationships were obtained for children from data reported in different studies performed at different times and at different geographic settings. Figures 1 and 2 show that DUFE is a linear function of TDFI for children and adults, although the numerical values for the intercepts and slopes are significantly different for both age groups (table 4). Figures 3-6 are presented for visual inspection only since, from equations 2-6 derived in the subsection 'Mathematical Calculations', it can be seen that the most relevant parameters can be arithmetically derived from the numerical values of the linear fits of figures 1 and 2 (table 4).

In order to illustrate the consistency of the numerical relationship between DUFE and TDFI obtained for children in this current study with previously proposed provisional standards [Marthaler, 1999] for urinary fluoride excretion that are considered 'optimal' for 3- to 5- and 6to 7-year-olds, the range of values for the DUFE proposed in the WHO monograph can be examined further. The ranges of the values given are $0.36-0.48$ and $0.48-0.60$ $\mathrm{mg} F /$ day, respectively. When these lower and upper limits are introduced into the linear regression of DUFE versus TDFI for children (table 4), the estimated average 
TDFI lie in the range of $0.91-1.26$ and $1.26-1.60 \mathrm{mg}$ F/day for 3- to 5- and 6- to 7-year-old children, respectively. Taking 16 and $22 \mathrm{~kg}$ as the average body weight for a 4 and a 6.5-year-old child, respectively, the ranges of average daily fluoride doses for these two age groups can be estimated to be $0.057-0.077$ and $0.057-0.072 \mathrm{mg} / \mathrm{kg}$ body weight/day, respectively. These latter values are in good agreement with the so-called optimal range of daily fluoride dose [Burt, 1992].

From equation 5 and the slope and intercept values from table 4 , it is possible to estimate the value of TDFI that would yield a neutral daily fluoride balance, i.e. FFR equal to zero, in children. This estimated value is approximately $0.07-0.1 \mathrm{mg}$ F/day. For TDFI higher than about $0.1 \mathrm{mg}$ F/day, a positive fluoride balance will be established, while for TDFI lower than about $0.1 \mathrm{mg}$ F/day negative fluoride balances are predicted. This conclusion is in line with previously reported data on breast-fed infants [Ekstrand et al., 1984]. The same estimation can be made for adults. In this case, neutral fluoride balance would occur at TDFI of about $0.8 \mathrm{mg} \mathrm{F} /$ day. It is remarkable that when the values of TDFI leading to neutral fluoride balances in children and adults are divided by typical average body weights (the so-called fluoride daily dose) for these two age groups, very similar values of about $0.01 \mathrm{mg}$ $\mathrm{F} / \mathrm{kg}$ body weight are obtained, irrespective of age. It is clear from figure 3 (and fig. 4 for adults) that body fluoride retention $(\mathrm{mg} /$ day) increases linearly when fluoride intakes (mg/day) increase, while for very low fluoride intakes negative fluoride retentions are obtained, as previously reported [Ekstrand et al., 1984; Maguire et al., 2007].

When the proportion of TDFI that is retained is considered, figures 5 and 6 show the relationship between FFR and TDFI for children and adults, respectively. Both figures show common, interesting features. At a TDFI lower than approximately $0.5 \mathrm{mg} F /$ day, there is a steep increase in the FFR (including negative values) with increasing TDFI for children and adults. For TDFI values higher than approximately $0.5 \mathrm{mg} \mathrm{F} /$ day for children and $2 \mathrm{mg} \mathrm{F} /$ day for adults, the estimated FFR tends to reach limiting constant values independently of how high the TDFI is. Introducing the slopes and their 95\% CI from figures 1 and 2 into equation 6 , the constant FFR limiting values are found to be $0.55( \pm 0.03)$ and $0.36( \pm 0.02)$ for children and adults, respectively. The main conclusion is that irrespective of how high the TDFI might be, beyond approximately $0.5 \mathrm{mg}$ F/day for children and approximately $2 \mathrm{mg}$ F/day for adults, a constant proportion of it will be retained in children (0.55) and adults (0.36). More- over, these latter values might be considered 'upper limits' since they were obtained assuming a constant average $90 \%$ absorption of fluoride. If a lower fluoride absorption from a given TDFI is considered, then lower FFR limiting values would be obtained.

The estimation of the limiting FFR value (0.36) at high fluoride intakes found in adults might be of interest. This latter value shows that daily FFR in adults will not be higher than approximately $36 \%$ of the total intake irrespectively of how high the fluoride intake might be above a threshold intake of $2 \mathrm{mg}$ F/day. This quantitative finding is lower than the previously generally mentioned approximate value of 0.5 [Ekstrand, 1996; Whitford, 1996] and might become relevant when speculations are made on the accumulation of fluoride in human hard tissues. On the other hand, this finding is in line with recently reported FFR values for adults living in 'optimally' fluoridated areas [Villa et al., 2008].

The simple linear relationships found in this study for estimating TDFI, DFR and FFR from average DUFE measurements, including all the available information hitherto reported, represent an initial step towards the use of urinary fluoride excretion as a useful tool in epidemiological surveillance. However, further information would enhance their value greatly. For example, it appears reasonable to suggest that additional DUFE and TDFI studies should be performed on children older than 7 years and adolescents to explore how these two variables are related in 7- to 17-year-olds. Also, it appears that further studies of fluoride intake and urinary excretion in children, adolescents and adults residing in middle-eastern and/or Asiatic areas where vegetarian diets prevail would improve understanding of the relationship between type of diet, the above variables and fluorosis risk. Finally, the numerical features of the proposed models could be improved by performing additional studies on children, adolescents and adults living in communities where the naturally occurring drinking water fluoride concentrations are higher than the range examined in this work.

\section{Acknowledgement}

This study was supported by the Borrow Foundation, UK. 


\section{References}

American Academy of Pediatrics: Committee on nutrition, fluoride supplementation. Pediatrics 1986;77:758-761.

- Awadia AK, Haugejordan O, Bjorvatn K, Birkeland JM: Vegetarianism and dental fluorosis in a high fluoride area of northern Tanzania. Int J Paediatr Dent 1999;9:3-11.

Burt BA: The changing patterns of systemic fluoride intake. J Dent Res 1992;71(spec issue):1228-1237.

Burt BA, Fejerskov O: Water fluoridation; in Fejerskov O, Ekstrand J, Burt B (eds): Fluoride in Dentistry, ed 2. Copenhagen, Munksgaard, 1996, pp 275-290.

Do LG, Spencer AJ: Risk-benefit balance in the use of fluoride among young children. J Dent Res 2007;86:723-728.

Ekstrand J: Fluoride metabolism; in Fejerskov O, Ekstrand J, Burt B (eds): Fluoride in Dentistry, ed 2. Copenhagen, Munksgaard, 1996, pp 55-68.

Ekstrand J, Hardell LI, Spak CJ: Fluoride balance studies on infants in a 1-ppm-water-fluoride area. Caries Res 1984;18:87-92.

-Ekstrand J, Ziegler EE, Nelson SE, Fomon SJ: Absorption and retention of dietary and supplemental fluoride by infants. Adv Dent Res 1994;8:175-180.

Fawell J, Bailey K, Chilton J, Dahi E, Fewtrell L, Magara Y: Fluoride in Drinking Water. London, WHO, IWA Publishing, 2006.

-Franco AM, Saldarriaga A, Martignon S, González MC, Villa AE: Fluoride intake and fractional urinary fluoride excretion of Colombian preschool children. Community Dent Health 2005;22:272-278.

- Haftenberger M, Viergutz G, Neumeister V, Hetzer G: Total fluoride intake and urinary excretion in German children aged 3-6 years. Caries Res 2001;35:451-457.

-Hodge HC, Smith FA: Occupational fluoride exposure. J Occup Med 1977;19:12-39.
Maguire A, Zohouri FV, Hindmarch PN, Hatts J, Moynihan PJ: Fluoride intake and urinary excretion in 6- to 7-year-old children living in optimally, sub-optimally and non-fluoridated areas. Community Dent Oral Epidemiol 2007;35:479-488.

Maheshwari UR, McDonald JT, Schneider VS, Brunetti AJ, Leybin L, Newbrun E, Hodge HC: Fluoride balance studies in ambulatory healthy men with and without fluoride supplements. Am J Clin Nutr 1981;34:2679_ 2684.

Marthaler TM (ed): Monitoring of renal fluoride excretion in community preventive programmes on oral health. Geneva, World Health Organization, 1999.

Levy SM, Warren JJ, Davies CS, Kirchner L, Kanellis MJ, Wefel JS: Patterns of fluoride intake from birth to 36 months. J Public Health Dent 2001;61:70-77.

National Research Council: Fluoride in drinking water: a scientific review of EPA's standards. Committee on fluoride in drinking water. Washington DC, National Academies Press, 2006.

Ockerse T: Endemic Fluorosis in South Africa thesis, University of Witwatersrand, Pretoria, Government Printers, 1946.

Rodrigues MHC, Leite AL, Arana A, Villena RS, Forte FDS, Sampaio FC, Buzalaf MAR: Dietary fluoride intake by children receiving different sources of systemic fluoride. J Dent Res 2009;88:142-145.

-Spencer H, Lewin I, Wiatrowski E, Samachson J: Fluoride metabolism in man. Am J Med 1970;49:807-813.

Spencer H, Kramer L, Osis D, Wiatrowski E: Excretion of retained fluoride in man. J App Physiol 1975;38:282-287.

Srikantia SG, Siddiqui AH: Metabolic studies in skeletal fluorosis. Clin Sci 1965;28:477-485.
Villa AE, Anabalón M, Cabezas L: The fractional urinary fluoride excretion in young children under stable fluoride intake conditions. Community Dent Oral Epidemiol 2000;28: 344-355.

Villa AE, Anabalón M, Rugg-Gunn A: Fractional urinary fluoride excretion of young female adults during the diurnal and nocturnal periods. Caries Res 2008;42:275-281.

Villa AE, Cabezas L, Anabalón M, Garza E: The fractional urinary fluoride excretion of adolescents and adults under customary fluoride intake conditions, in a community with $0.6 \mathrm{mg} \mathrm{F} / \mathrm{l}$ in its drinking water. Community Dent Health 2004;21:11-18.

Whelton HP, Ketley CE, McSweeney F, O'Mullane DM: A review of fluorosis in the $\mathrm{Eu}-$ ropean Union: prevalence, risk factors and aesthetic issues. Community Dent Oral Epidemiol 2004;32(suppl 1):9-18.

Whitford GM: The physiological and toxicological characteristics of fluoride. J Dent Res 1990;69(spec issue):539-549.

Whitford GM: The Metabolism and Toxicity of Fluoride, ed 2, revised. Basel, Karger, 1996.

WHO: Fluorides and oral health. Technical Report Series 846. Geneva, World Health Organization, 1994.

Zohouri FV, Maguire A, Moynihan PJ: Fluoride content of still bottled waters available in the north-east of England, UK. Br Dent J 2003; 195:515-518.

Zohouri FV, Rugg-Gunn AJ: Total fluoride intake and urinary excretion in 4-year-old Iranian children residing in low-fluoride areas. Br J Nutr 2000;83:15-25.

Zohouri FV, Swinbank CM, Maguire A, Moynihan PJ: Is the fluoride/creatinine ratio of a spot urine sample indicative of 24-h urinary fluoride? Community Dent Oral Epidemiol 2006;34:130-138. 